\title{
O estado da saúde pública explica o julgamento do eleitor?
}

Does the state of public health explain the judgment of the voter?

\section{Adriano Oliveira \\ Carlos Gadelha \\ Simara Costa}

\section{Resumo}

Através de pesquisas quantitativas realizadas nas cidades do Recife, Maceió e Santa Cruz do Capibaribe e do teste estatístico do Qui-quadrado mostramos associação existente entre os julgamentos dos eleitores para com a gestão do prefeito e a avaliação do serviço de saúde. Isto significa que prefeitos que cuidam da saúde constroem condiçóes adequadas para a sua reeleição. Este artigo revela que a identificação espontânea por parte do eleitor do principal problema do município não é relevante para decifrarmos as razóes que o motiva a julgar o alcaide. Porém, a identificação do problema de maneira espontânea no universo dos usuários dos serviços de saúde é relevante para decifrar as razóes do julgamento da gestáo do prefeito.

\section{Palavras-chave}

Julgamento dos Eleitores; Avaliação da Administração; Usuários do Serviço Público de Saúde.

\begin{abstract}
Through quantitative surveys carried out in the cities of Recife, Maceió and Santa Cruz do Capibaribe and the statistical test of Chi-square, we show an association between the voters' judgments regarding the mayor's management and the evaluation of the health service. This means that mayors who take care of health create suitable conditions for their re-election. This article reveals that spontaneous identification by the voter of the main problem of the municipality is not relevant to decipher the reasons that motivate him to judge the mayor. However, identifying the problem spontaneously in the universe of health service users is relevant to deciphering the reasons for the judgment of the mayor's management.
\end{abstract}

\section{Keywords}

Judgment of the Voters; Evaluation of the Administration; Users of the Public Health Service. 


\section{Introdução}

Existe associação entre o julgamento da gestáo do prefeito e a avaliação do serviço público de saúde do município? Existe associação entre o principal problema da cidade e o julgamento da gestáo do alcaide? Este artigo tem o objetivo principal de responder estas indagaçōes.

Almeida (2008) traz importante premissa para explicar os julgamentos e as escolhas dos eleitores: gestores bem avaliados tendem a ser reeleitos. $\mathrm{O}$ gestor pode ser o presidente da República, o governador ou o prefeito. Náo importa o cargo. Se ele estiver bem avaliado, a reeleição tende a ocorrer.

A premissa de Almeida (2008) corrobora com a do voto retrospectivo (FIORINA, 1981). Esta premissa considera que eleitores olham para o passado e o presente e julgam os gestores. Se o julgamento for positivo, existe forte probabilidade de o eleitor votar pela reeleição do prefeito, por exemplo.

Gramacho, Jácomo e Sampaio. (2016) utilizam as premissas dos citados autores para mostrar a relaçáo entre aumento de passagens do transporte público e popularidade do prefeito. Telles, Fraiha e Lopes (2016) mostram que escândalos de corrupção não interferem fortemente na escolha do eleitor na eleição municipal. Oliveira e Gadelha (2016) revelam que determinados hábitos do eleitor estáo associados ao julgamento que eles fazem da administração do prefeito. Eleitores têm informações suficientes para fazer julgamentos quanto à avaliação de dado serviço público? Caso eles não tenham, o julgamento dos eleitores sobre determinado serviço público e a gestáo do prefeito pode não corresponder à verdade (ACHEN e BARTELS, 2016). Neste artigo, buscamos comprovar as seguintes hipóteses:

- A aprovaçáo ou a reprovação do prefeito depende da avaliação do serviço público de saúde realizado pelos eleitores;

- A aprovação ou a reprovação do alcaide depende do principal problema da cidade apontado pelos eleitores.

Com o objetivo de responder aos problemas propostos e testar as hipóteses apresentadas, buscamos avaliar os serviços de saúde em três cidades. $\mathrm{O}$ teste das hipóteses em mais de uma cidade, oferta confiabilidade às respostas advindas dos problemas de pesquisas apresentados. A disponibilidade de pesquisas influenciou a escolha das seguintes localidades ${ }^{1}$ : Recife, capital do estado de Pernambuco; Maceió,

\footnotetext{
${ }^{1}$ Agradecemos a Cenário Inteligência e ao Instituto de Pesquisa Maurício de Nassau (IPMN) pela disponibilidade dos dados. Desde janeiro de 2017, o IPMN passou a ser Instituto de Pesquisa Uninassau.
} 
capital do estado de Alagoas; e Santa Cruz do Capibaribe, cidade localizada em Pernambuco ${ }^{2}$.

As pesquisas realizadas identificaram entre os eleitores o principal problema da cidade, a qualidade do serviço público de saúde entre os usuários e a avaliação da gestáo do prefeito. Com a utilização do teste estatístico Qui-Quadrado, consideramos, com o propósito de responder as indagaçóes expostas, e testar as hipóteses exibidas, que existe associação significativa entre as variáveis (1) Julgamento dos eleitores da gestão do prefeito e (2) Avaliação do sistema público de saúde. E também associação significativa entre (1) Julgamento dos eleitores da gestão do prefeito e o (2) Principal problema da cidade. O teste estatístico Qui-Quadrado tem o objetivo de evidenciar associaçóes entre duas variáveis. Se a variável A cresce, a variável $\mathrm{B}$ também cresce, por exemplo. Em razão da associação, observamos também relação de dependência.

Este artigo está dividido em três partes. Considerando pesquisas quantitativas realizadas em Recife, Maceió e Santa Cruz do Capibaribe, apresentamos, inicialmente, a opiniáo do eleitor sobre o principal problema da cidade, o porcentual dos usuários do serviço público de saúde com base no survey realizado, o julgamento da qualidade do serviço de saúde por parte dos usuários pesquisados, e o julgamento da gestão dos alcaides.

Em seguida, realizamos o teste estatístico Qui-Quadrado para responder aos problemas propostos. Nesta parte, fazemos a análise dos dados. Por fim, apresentamos a conclusão. Este artigo conclui apresentando as razóes da necessidade prioritária de considerar a avaliação dos serviços públicos por parte dos que utilizam para a compreensão das razóes que motivam eleitores aprovarem ou não gestores. $\mathrm{E}$ mostramos que serviço de saúde pública aprovado condiciona novo sucesso eleitoral para o incumbente.

\section{A saúde pública e os eleitores}

A verbalizaçáo espontânea do principal problema da cidade mostra que parte dos eleitores está ciente das suas demandas. Quando coletamos a opinião dos que utilizaram dado serviço público nos aproximamos da verdade avaliativa, visto que foram os usuários do serviço público que opinaram sobre a qualidade dele.

Ao indagarmos os eleitores sobre o principal problema da cidade, encontramos as seguintes respostas: $28,2 \%$ dos eleitores do Recife apontam a saúde

\footnotetext{
${ }^{2}$ As pesquisas foram realizadas nas cidades em épocas diferentes.
} 
pública e 25,2\% a segurança pública ${ }^{3}$. Em Maceió, 28,9\% afirmam que é a segurança pública e $27,4 \%$ a saúde 4 . Na cidade de Santa Cruz do Capibaribe, 50,6\% asseveram que é a segurança pública e $19,1 \%$ a saúde 5 . Conforme tabela 1 abaixo:

Tabela 1 - Principal problema da cidade

\begin{tabular}{c|c|c|c}
\hline $\begin{array}{c}\text { Qual é o principal problema da sua } \\
\text { cidade? }\end{array}$ & Recife & Maceió & $\begin{array}{c}\text { Santa Cruz do } \\
\text { Capibaribe }\end{array}$ \\
\hline Saúde & $28,2 \%$ & $28,9 \%$ & $19,1 \%$ \\
\hline Segurança pública & $25,2 \%$ & $27,4 \%$ & $50,6 \%$ \\
\hline
\end{tabular}

Fonte: Cenário Inteligência e Instituto de Pesquisa Maurício de Nassau, 2015 e 2016.

Conforme questionário aplicado, perguntou-se "Você, nos últimos seis meses, foi a um posto de saúde da prefeitura do Recife?" ". Cerca de $40 \%$ dos eleitores afirmaram que sim e $60 \%$ que não. Entre os eleitores com renda até um salário mínimo $(1 \mathrm{SM})^{7}, 57 \%$ afirmaram que foram a um posto de saúde nos últimos seis meses. $44 \%$ dos eleitores com renda entre 1 a 2 SM afirmaram que estiveram no posto de saúd, e, entre os eleitores com 2 a $5 \mathrm{SM}$ e acima de $5 \mathrm{SM}$, responderam sim $33 \%$ e $24 \%$, respectivamente ${ }^{8}$. Os dados revelam que quanto maior a renda, menor o porcentual de pessoas que foram ao posto de saúde nos últimos seis meses.

Em Maceió, capital do estado de Alagoas, no mês de outubro de 2015, 43\% dos eleitores afirmaram que foram a um posto de saúde da cidade de Maceió nos

\footnotetext{
${ }^{3}$ Pesquisa realizada na cidade do Recife nos dias 25 e 26 de abril de 2016. 624 entrevistas foram realizadas. Foram entrevistados eleitores com 16 anos ou mais de idade em áreas de abrangência da pesquisa. A amostra foi selecionada a partir de um plano de amostragem estratificada de conglomerados em dois estágios. No primeiro estágio foram sorteados os setores censitários e em seguida é selecionado um número fixo de pessoas segundo cotas amostrais das variáveis sexo e faixa etária. O número de entrevistas foi estabelecido com base em uma amostragem aleatória simples com um nível estimado de $95 \%$ de confiança e uma margem de erro estimada de 4 pontos percentuais. A amostra foi definida com base nas fontes oficiais de dados: Censo IBGE, TSE e TRE.

${ }^{4}$ Pesquisa realizada na cidade de Maceió nos dias 07 e 08 de outubro de 2015.597 entrevistas foram realizadas. A margem de erro estimada de 4 pontos percentuais. A metodologia foi a mesma aplicada na cidade do Recife.

${ }^{5}$ Pesquisa realizada na cidade de Santa Cruz do Capibaribe nos dias 10 e 11 de março de 2016. 624 entrevistas foram realizadas. A margem de erro estimada é de 4 pontos percentuais. A metodologia foi a mesma aplicada nas cidades do Recife e Maceió.

${ }^{6}$ Esta indagação consta no questionário de pesquisa que foi aplicado entre os eleitores.

${ }^{7} \mathrm{SM}$ significa salário mínimo.

${ }^{8} 76 \%$ dos eleitores com renda acima de 5 salários mínimos (SM), afirmaram que não foram ao posto de saúde nos últimos seis meses.
} 
últimos seis meses, 55\% asseveraram que não e 65\% dos entrevistados que declararam ter renda até $1 \mathrm{SM}$ afirmaram que foram nos últimos seis meses a um posto de saúde. Dos que têm renda entre 1 a 2 SM, $42 \%$ frisaram que foram, $26 \%$ dos eleitores com renda entre 2 a 5 SM responderam que sim e $8 \%$ dos eleitores com renda acima de 5 SM asseveraram que foram ao posto de saúde. Portanto, quanto menor a renda, maior a frequência ao posto de saúde, assim como constatamos na capital pernambucana.

$\mathrm{Na}$ cidade de Santa Cruz do Capibaribe, 38\% dos entrevistados declararam que foram a um posto de saúde nos últimos seis meses e $62 \%$ responderam que não foram. O eleitor com renda até $1 \mathrm{SM}$ é o que mais frequenta o posto de saúde, são $38 \%$. Neste município, observamos que $24 \%$ dos eleitores com renda superior a 5 SM foram até ao posto de saúde. Tal dado distorce das outras cidades apresentadas, pois, comparativamente, o porcentual é mais alto. Dos eleitores que declaram ter frequentado o posto de saúde, $40 \%$ é com renda entre 1 a 2 SM e $39 \%$ com rendimentos entre 2 a 5 SM.

Tabela 2 - Frequência ao posto de saúde nos últimos seis meses

\begin{tabular}{c|c|c|c}
\hline $\begin{array}{c}\text { Você nos últimos seis meses foi a um posto } \\
\text { de saúde pública? }\end{array}$ & Recife & Maceió & $\begin{array}{c}\text { Santa Cruz do } \\
\text { Capibaribe }\end{array}$ \\
\hline Sim & $60 \%$ & $43 \%$ & $38 \%$ \\
\hline Náo & $40 \%$ & $55 \%$ & $62 \%$ \\
\hline
\end{tabular}

Fonte: Cenário Inteligência e Instituto de Pesquisa Maurício de Nassau, 2015 e 2016.

Em sua avaliação, "O posto de saúde do Recife é...?” Esta indagação foi realizada exclusivamente para os eleitores que afirmaram que foram a um posto de saúde nos últimos seis meses, ou seja, $60 \%$. A pesquisa realizada oferecia as seguintes opçôes aos entrevistados: ótimo, bom, regular, ruim e péssimo. Sendo que $9 \%$ dos usuários aprovaram o posto de saúde (bom $)^{9}, 36 \%$ consideraram regular e 55\% (ruim/péssimo) reprovaram o posto de saúde. A pesquisa revelou que 39\% dos eleitores aprovavam a gestão do prefeito Geraldo Júlio ${ }^{10}$, e $56 \%$ desaprovavam.

No universo, $43 \%$ dos eleitores declararam que foram ao posto de saúde nos últimos seis meses na cidade de Maceió. Destes, '16\% (ótimo/bom) aprovaram o posto de saúde, $41 \%$ o consideraram regular e $42 \%$ o reprovaram. Esta pesquisa

\footnotetext{
${ }^{9}$ Não existiu referência à categoria Ótima.

${ }^{10} \mathrm{O}$ prefeito Geraldo Julio é filiado ao Partido Socialista Brasileiro (PSB).
} 
revela também que $41 \%$ dos eleitores aprovavam a gestáo do prefeito Rui Palmeira ${ }^{11}$ e $48 \%$ reprovavam.

A avaliação de que os eleitores santa-cruzenses fizeram do posto de saúde foram: $51 \%$ (ótimo/bom) aprovam o posto de saúde, 19\% reprovam (péssimo/ruim) e $30 \%$ consideram regular. A pesquisa revelou que o prefeito Edson Vieira ${ }^{12}$ tem a sua gestão aprovada por $47 \%$ dos eleitores e $45 \%$ a reprovam.

Tabela 3 - Avaliação do posto de saúde

\begin{tabular}{c|c|c|c}
\hline Em sua avaliaçáo, o posto de saúde é? & Recife & Maceió & $\begin{array}{c}\text { Santa Cruz do } \\
\text { Capibaribe }\end{array}$ \\
\hline Ótimo & $0 \%$ & $2 \%$ & $9 \%$ \\
\hline Bom & $9 \%$ & $14 \%$ & $42 \%$ \\
\hline Regular & $36 \%$ & $41 \%$ & $30 \%$ \\
\hline Ruim & $31 \%$ & $23 \%$ & $13 \%$ \\
\hline Péssimo & $24 \%$ & $19 \%$ & $6 \%$ \\
\hline
\end{tabular}

Fonte: Cenário Inteligência e Instituto de Pesquisa Maurício de Nassau, 2015 e 2016.

Tabela 4 - Avaliação da gestão do prefeito

\begin{tabular}{c|c|c|c}
\hline Avaliaçáo da gestáo do prefeito & Recife & Maceió & $\begin{array}{c}\text { Santa Cruz do } \\
\text { Capibaribe }\end{array}$ \\
\hline Aprovam a gestáo & $39 \%$ & $41 \%$ & $47 \%$ \\
\hline Reprovam a gestáo & $56 \%$ & $48 \%$ & $45 \%$ \\
\hline
\end{tabular}

Fonte: Cenário Inteligência e Instituto de Pesquisa Maurício de Nassau, 2015 e 2016.

\section{O estado da saúde pública e o principal problema da cidade explicam o julgamento do eleitor?}

Os dados descritivos apresentados mostram que saúde pública é o principal problema das cidades de Recife e Maceió. O principal problema de Santa Cruz do Capibaribe é a segurança pública. Nas capitais de Pernambuco e Alagoas estáo os maiores percentuais de eleitores que declaram ter frequentado o posto de saúde nos últimos seis meses: $60 \%$ e $43 \%$, respectivamente.

Em Santa Cruz do Capibaribe, $60 \%$ dos eleitores afirmam não ter frequentado o posto de saúde no período referido. Nesta cidade, está presente, também, o maior percentual de eleitores que aprovam os serviços do posto de saúde.

\footnotetext{
${ }^{11}$ O prefeito Rui Palmeira é filiado ao Partido Social Democrata do Brasil (PSDB).

${ }^{12} \mathrm{O}$ prefeito Edson Vieira é filiado ao Partido Social Democrata do Brasil (PSDB).
} 
Em Santa Cruz do Capibaribe existe o menor percentual de eleitores que apontam a saúde pública como principal problema.

Os dados referentes a Santa Cruz do Capibaribe sugerem que quanto menor o porcentual de pessoas que frequentam o posto de saúde, menor o número de pessoas que declaram a saúde púbica como o principal problema. Ou seja: a frequência ao posto dimensiona ou não saúde como principal problema. A Tabela 5 mostra associaçôes significativas entre "principal problema" versus "frequência ao posto de saúde”. Tal associação sugere que quando o eleitor identifica a saúde como principal problema do município, ele faz em razão de ter utilizado recentemente o serviço de saúde. Maior porcentual de pessoas que frequenta o posto de saúde está associado ao maior porcentual de eleitores que afirmam que saúde pública é o principal problema da cidade.

Tabela 5 - Principal problema da cidade versus Frequência ao posto de saúde

\begin{tabular}{l|l|c|c|c}
\hline \multirow{2}{*}{ Cidade } & $\begin{array}{c}\text { Principal problema } \\
\text { é a saúde? }\end{array}$ & \multicolumn{2}{|c|}{$\begin{array}{c}\text { Frequentou posto de saúde de seu } \\
\text { município nos últimos seis meses? }\end{array}$} & \\
\cline { 2 - 4 } & & SIM & NÁO & p-valor \\
\hline \multirow{2}{*}{ Recife } & SIM & $42,6 \%$ & $18,9 \%$ & \multirow{2}{*}{$0,000^{*}$} \\
\cline { 2 - 4 } & NÃO & $57,4 \%$ & $81,1 \%$ & \multirow{2}{*}{$0,016^{*}$} \\
\hline \multirow{2}{*}{ Maceió } & SIM & $34,5 \%$ & $24,9 \%$ & \multirow{2}{*}{$0,009^{*}$} \\
\cline { 2 - 4 } & NÃO & $65,5 \%$ & $75,1 \%$ & $16,1 \%$ \\
\hline \multirow{2}{*}{$\begin{array}{l}\text { Santa Cruz do } \\
\text { Capibaribe }\end{array}$} & SIM & $24,7 \%$ & $83,9 \%$ & \\
\cline { 2 - 4 } & NÃO & $75,3 \%$ & &
\end{tabular}

${ }^{*}$ p-valor $<0,05$, há associação estatisticamente significativa entre as variáveis.

Fonte: Cenário Inteligência e Instituto de Pesquisa Maurício de Nassau, 2015 e 2016.

Como bem mostra a Tabela 5, 24,7\% dos usuários santa-cruzenses do serviço de saúde apontam a saúde como principal problema do município. Portanto, a frequência ao posto de saúde está associada com a dimensão da saúde como principal problema da cidade, conforme assertiva anteriormente realizada. No universo dos usuários que aprovam o serviço público de saúde, o prefeito tem aprovação da gestáo maior do que a reprovaçáo. Considerando a Tabela 6 a seguir, constatamos que os alcaides têm aprovação maior entre os eleitores que aprovam o serviço público de saúde. Quando ocorre a reprovaçáo do serviço de saúde, o prefeito encontra alta rejeição. Portanto, a primeira hipótese deste artigo é comprovada, pois existe associação entre as duas variáveis, conforme mostra o teste do Qui-quadrado. 
74 | Adriano Oliveira, Carlos Gadelha e Simara Costa

Tabela 6 - Julgamento da gestão do prefeito versus Avaliação do serviço público de saúde

\begin{tabular}{l|l|c|c|c|c}
\hline \multirow{2}{*}{ Cidade } & \multirow{2}{*}{$\begin{array}{l}\text { Avaliaçáo da } \\
\text { gestáo }\end{array}$} & \multicolumn{2}{|c|}{ Avaliaçáo do serviço público de saúde } & \\
\cline { 2 - 5 } & Ótimo/Bom & Regular & Ruim/Péssimo & \multirow{2}{*}{-valor } \\
\hline \multirow{2}{*}{ Recife } & Aprovo & $61,9 \%$ & $44,0 \%$ & $19,2 \%$ & \multirow{2}{*}{$0,000^{*}$} \\
\cline { 2 - 5 } & Desaprovo & $38,1 \%$ & $56,0 \%$ & $80,8 \%$ & \\
\hline \multirow{2}{*}{$\begin{array}{l}\text { Maceió } \\
\text { Santa Cruz do }\end{array}$} & Aprovo & $78,4 \%$ & $58,0 \%$ & $40,2 \%$ & \multirow{2}{*}{$0,000^{*}$} \\
\cline { 2 - 5 } & Desaprovo & $21,6 \%$ & $42,0 \%$ & $59,8 \%$ & \\
\cline { 2 - 5 } & Aprovo & $81,4 \%$ & $30,3 \%$ & $26,3 \%$ & \multirow{2}{*}{$0,000^{*}$} \\
\hline
\end{tabular}

${ }^{*}$ p-valor $<0,05$, há associação estatisticamente significativa entre as variáveis.

Fonte: Cenário Inteligência e Instituto de Pesquisa Maurício de Nassau, 2015 e 2016.

A segunda hipótese deste artigo é: a aprovação ou reprovação do alcaide depende do principal problema da cidade apontado pelos eleitores. $\mathrm{Na}$ cidade do Recife, a hipótese é comprovada, pois 66,9\% dos eleitores reprovam a gestão do prefeito no universo dos eleitores que declaram que a saúde pública é o principal problema e também existe associação significativa entre as variáveis conforme exposto na Tabela 7 .

Contudo, em Maceió e Santa Cruz do Capibaribe não existem associações significativas e os gestores são aprovados no universo dos eleitores que apontam a saúde pública como o principal problema. Portanto, a hipótese apresentada não é comprovada em Maceió e em Santa Cruz do Capibaribe, ela é verossímil, apenas, na capital pernambucana.

Tabela 7 - Julgamento da gestáo do prefeito versus Principal problema da cidade

\begin{tabular}{l|l|c|c|c}
\hline \multirow{2}{*}{ Cidade } & $\begin{array}{l}\text { Avaliaçáo da } \\
\text { gestáo }\end{array}$ & Principal problema é a saúde? & \\
\cline { 2 - 4 } & Aprovo & $33,1 \%$ & NÃO & p-valor \\
\hline \multirow{2}{*}{ Recife } & Desaprovo & $\mathbf{6 6 , 9 \%}$ & $54,2 \%$ & \multirow{2}{*}{$0,014^{*}$} \\
\hline \multirow{2}{*}{ Maceió } & Aprovo & $\mathbf{5 2 , 1 \%}$ & $43,8 \%$ & \\
\cline { 2 - 4 } & Desaprovo & $47,9 \%$ & $56,8 \%$ & \multirow{2}{*}{0,071} \\
\hline \multirow{2}{*}{$\begin{array}{l}\text { Santa Cruz do } \\
\text { Capibaribe }\end{array}$} & Aprovo & $\mathbf{5 7 , 9 \%}$ & $48,7 \%$ & \multirow{2}{*}{0,078} \\
\cline { 2 - 4 } & Desaprovo & $42,1 \%$ & $51,3 \%$ & \\
\hline
\end{tabular}

* p-valor $<0,05$, há associação estatisticamente significativa entre as variáveis.

Fonte: Cenário Inteligência e Instituto de Pesquisa Maurício de Nassau, 2015 e 2016.

Com o teste de hipóteses realizado, adquirirmos condições de responder as duas indagaçóes do artigo, quais sejam: existe relação entre a avaliação dos serviços 
públicos de saúde do município e o julgamento da gestão do prefeito? Existe relação entre o principal problema da cidade e o julgamento da gestão do alcade? Para a primeira indagação, a resposta é sim. Quanto à segunda, a resposta é não.

Apesar da contemplaçáo dos objetivos deste artigo, ou seja, o teste das hipóteses e as respostas para as indagaçôes, o falseamento da segunda hipótese e os resultados observados em Santa Cruz do Capibaribe nos incentivam a construir indagaçôes e reflexóes sobre os dados já apresentados com o intuito de construirmos conclusóes que contribuam fortemente para pesquisas sobre o comportamento do eleitor.

Ao olharmos a Tabela 8 a seguir, verificamos que não existe associação significativa entre as variáveis "avaliação da gestão" versus "segurança pública como principal problema da cidade", assim como não ocorreu entre as variáveis Avaliação da gestáo versus saúde pública como principal problema da cidade, com exceção do Recife (conforme exposto na Tabela 7).

Tabela 8 - Julgamento da gestáo do prefeito versus Principal problema da cidade

\begin{tabular}{l|l|c|c|c}
\hline \multirow{2}{*}{ Cidade } & \multicolumn{1}{|c|}{ Avaliaçáo da } & \multicolumn{2}{|c|}{ Principal problema é a segurança? } & \\
\cline { 2 - 4 } & \multicolumn{1}{|c}{ Gestáo } & SIM & NĂO & p-valor \\
\hline \multirow{2}{*}{ Recife } & Aprovo & $41,2 \%$ & $41,0 \%$ & \multirow{2}{*}{0,955} \\
\cline { 2 - 4 } & Desaprovo & $\mathbf{5 8 , 8 \%}$ & $59,0 \%$ & \\
\hline \multirow{2}{*}{ Maceió } & Aprovo & $48,7 \%$ & $44,5 \%$ & \multirow{2}{*}{0,385} \\
\cline { 2 - 4 } & Desaprovo & $\mathbf{5 1 , 3 \%}$ & $55,5 \%$ & \multirow{2}{*}{0,204} \\
\hline \multirow{2}{*}{$\begin{array}{l}\text { Santa Cruz do } \\
\text { Capibaribe }\end{array}$} & Aprovo & $\mathbf{4 7 , 9 \%}$ & $53,3 \%$ & \\
\cline { 2 - 4 } & Desaprovo & $\mathbf{5 2 , 1 \%}$ & $46,7 \%$ & \\
\hline
\end{tabular}

${ }^{*}$ p-valor $<0,05$, há associação estatisticamente significativa entre as variáveis.

Fonte: Cenário Inteligência e Instituto de Pesquisa Maurício de Nassau, 2015 e 2016.

Os eleitores, independente da cidade, reprovam majoritariamente os gestores quando apontam a segurança pública como o principal problema. Portanto, os eleitores tendem a punir os prefeitos, ao contrário do que observamos no universo de eleitores que apontam a saúde pública. Entretanto, tal conclusão é frágil em razão de não existir associação entre as variáveis "avaliação da gestão" versus "principal problema”, conforme mostram as Tabelas 7 e 8 . Identificar o principal problema da cidade contribui para decifrar as razôes que motivam os julgamentos dos eleitores para com a gestão do prefeito? Este artigo mostra que não. 
76 | Adriano Oliveira, Carlos Gadelha e Simara Costa

\section{Conclusão}

Os surveys contribuem para elucidar os julgamentos dos eleitores para com a gestão municipal quando eles identificam os usuários de dado serviço público e posteriormente a avaliação que estes fazem do serviço. Este artigo mostrou que existe associação significativa entre as variáveis Avaliação da administração e Avaliaçáo do serviço público de saúde. Portanto, o julgamento que os eleitores fazem do serviço público contribui para a compreensão do julgamento destes para com a gestão do alcaide.

Não adianta indagar se eleitores aprovam ou não gestores públicos. É necessário que se apresente as razóes da aprovação. Este artigo mostrou que saúde pública bem avaliada está associada a aprovação de prefeitos. Portanto, prefeitos que qualificam o serviço público de saúde adquirem, conforme este artigo sugere, condiçóes de ser reeleitos. Esta premissa está baseada em Fiorina (1981) e Almeida (2008), os quais consideram a teoria do voto retrospectivo para predizer e explicar o sucesso ou não dos gestores candidatos à reeleição.

Este artigo tem uma inovaçáo importante. Ele mostra, através de surveys realizados em três cidades, a necessidade de avaliar os serviços públicos geridos pelo poder municipal considerando apenas os que utilizam o serviço. Ao fazermos isto, dividirmos os eleitores em dois grupos: os que têm informação para avaliar o serviço público e os que não têm. Os pertencentes ao último grupo não avaliam adequadamente o serviço público, já que supomos que eles não têm informaçóes suficientes para avaliá-lo.

A metodologia adotada pelos surveys utilizados neste artigo contribui para amenizar o problema da informaçáo no julgamento dos eleitores (ACHEN e BARTELS, 2016). Os eleitores têm informaçôes suficientes para julgar a gestão de prefeitos? Esta indagação é necessária para desenvolvermos metodologias que consigam decifrar satisfatoriamente os julgamentos que os eleitores fazem dos governos. Este artigo mostra que a avaliação dos serviços públicos por parte dos usuários é caminho importante para decifrar as razóes que orientam os julgamentos dos gestores por parte dos eleitores.

A indagação costumeiramente observada em surveys "Qual é o principal problema da cidade?” contribui fracamente para decifrar as razóes que motivam/condicionam os julgamentos dos eleitores, pois com exceção do Recife, não encontramos associação significativa entre as variáveis "avaliação da gestão" versus "principal problema da cidade”, especificamente saúde. Quando o principal problema 
da cidade é a segurança pública, não encontramos associação em nenhuma cidade abordada.

Destacamos, porém, que a utilização do serviço público de saúde contribui para que o eleitor identifique o principal problema da cidade. Encontramos associação significativa entre as variáveis "principal problema da cidade" versus "frequência ao posto de saúde nos últimos seis meses". Mostramos também que frequência ao posto de saúde contribui para explicar a dimensão do principal problema da cidade entre os eleitores.

Este artigo sugere que prefeitos que qualificam o sistema de saúde pública aumenta a chance de ser reeleito. Mostra indícios de que eleitores que utilizam serviços públicos, em particular o serviço de saúde pública, adquirem informaçóes para julgar gestores. E que as pesquisas eleitorais no Brasil devem inserir avaliação dos serviços públicos em seus questionários, pois ela contribui para explicar os julgamentos dos eleitores para com administração de candidatos à reeleição e, por consequência, clarifica as chances de sucesso eleitoral deles.

Adriano Oliveira é Doutor em Ciência Política pela Universidade Federal de Pernambuco (UFPE). Professor do Departamento de Ciência Política da UFPE. E-mail: adrianopolitica@uol.com.br.

- Carlos Gadelha é Mestre em Estatística pela UFPE. Estatístico do Instituto de Pesquisa Uninassau. E-mail: carlos.gadelh@hotmail.com

- Simara Costa é Mestre em Estatística pela Universidade Rural de Pernambuco. Estatística do Instituto de Pesquisa Uninassau. Email: simaracosta@hotmail.com

\section{Referências}

ALMEIDA, Alberto Carlos. A cabeça do eleitor: estratégia de campanha, pesquisa e vitória eleitoral. Rio de Janeiro: Record, 2008.

ACHEN, Christopher H; BARTELS, Larry M. Democracy for realists - Why elections do not produce responsive government. New Jersey: Princeton University Press, 2016.

Cenário Inteligência e Instituto de Pesquisa Maurício de Nassau, 2015 e 2016. 
78 | Adriano Oliveira, Carlos Gadelha e Simara Costa

GRAMACHO, Wladimir; JÁCOMO, André; SAMPAIO, Thiago. Tarifas e tarefas: determinantes locais e institucionais da aprovação do prefeito de São Paulo (1993-2002). In: LAVAREDA, Antonio. TELLES, Helcimara (Orgs.). A lógica das eleiçôes municipais. Rio de Janeiro: FGV, 2016.

FIORINA, Morris. Retrospective voting in American national elections. New Haven; London: Yale University, 1981.

OLIVEIRA, Adriano; GADELHA, Carlos. Os hábitos explicam os julgamentos e as escolhas dos eleitores? In: X Encontro de Ciência Politica (ABCP). Belo Horizonte, 2016.

TELLES, Helcimara; FRAIHA, Pedro Soares; LOPES, Nayla. Escândalos midiáticos de corrupção e pragmatismo: campanhas e voto para prefeito de Belo Horizonte. In: LAVAREDA, Antonio. TELLES, Helcimara (org). A lógica das eleiçóes municipais. Rio de Janeiro: FGV, 2016.

Texto recebido em 15 de fevereiro de 2017. Aprovado em 24 de março de 2017. 